\title{
Erratum
}

\section{Evidences for the control of chromosome number variation by a programmed-cell-death-like pathway in citrus callus}

\author{
Chromosome number variation in citrus callus
}

\author{
Yu-Jin Hao, Chun-Xiang You \& Xiu-Xin Deng
}

Euphytica, Vol. 140, No. 3, pp. 205-212 (2004)

Due to an unfortunate misunderstanding, the incorrect corresponding author was indicated in the header of the article mentioned above. The correct representation of the authors and their affiliations should have read:

\author{
Yu-Jin Hao ${ }^{1,2,4}$, Chun-Xiang You ${ }^{3} \&$ Xiu-Xin Deng ${ }^{1, *}$ \\ ${ }^{1}$ National Key Laboratory of Crop Genetic Improvement, Huazhong Agricultural University, Wuhan \\ 430070, P.R. China; ${ }^{2}$ PKU-Yale Joint Research Center of Agricultural Biotechnology and Plant Molecular \\ Biology, College of Life Sciences, Peking University, Beijing 100871, P.R. China; ${ }^{3}$ Laiyang Agricultural \\ College, Shandong 265200, P.R. China; ${ }^{4}$ Present address: Department of Plant, Cell and Environment, \\ National Institute of Fruit Tree Science, Fujimoto 2-1, Tsukuba, Ibaraki 305-8605, Japan; (*author for \\ correspondence: e-mail: xxdeng@mail.hzau.edu.cn)
}

Furthermore, there has been a misrepresentation of the legend of Figure 3 (page 211). The correct version of this legend is published below:

Figure 3. PCD in calli of 'Newhall' navel orange: A - positive control for TUNEL assay showing that all nuclei in a DNaseI-digested section are stained $(\mathrm{Bar}=47.34 \mu \mathrm{m}), \mathrm{B}-$ negative control absent of terminal deoxynucleotidyl transferase for TUNEL assay showing that no nuclei in a DNaseI-digested section is stained ( $\mathrm{Bar}=41.32 \mu \mathrm{m}), \mathrm{C}-$ section is stained with TUNEL assay. Arrows show that a few cells were undergoing PCD $($ Bar $=40.30 \mu \mathrm{m}), \mathrm{D}-$ a normal diploid cell $(2 \mathrm{X})$ and an abnormal tetraploid cell $(4 \mathrm{X})$ stained for DNA with DAPI $(\mathrm{Bar}=40 \mu \mathrm{m}), \mathrm{E}-$ a normal diploid cell $(2 \mathrm{X})$ and an abnormal tetraploid cell $(4 \mathrm{X})$ detected with comet electrophoresis. Tetraploid cell produces comet-shape tail $($ Bar $=37.5 \mu \mathrm{m})$. 